\title{
Chemistry Games with Kitchen Resources and Students' Academic Performance in Electronic Configuration
}

\author{
Cecilia O. N. (Ph.D), Kimson J. I. and Joy J. O. \\ Department of Science Education, University of Calabar, P.M.B 1115, Calabar, \\ Cross River State, Nigeria. njacecilia@gmail.com +2347037958296
}

\begin{abstract}
Chemistry games with kitchen resources and students' academic achievement in electronic configuration. Kitchen resources such as green, brown red, white and multi coloured beans were used to play electronic configuration games. The sample comprised of 100 students drawn from two secondary schools in Calabar Education Zone of Cross River State. The sample was made up of 60 females and 40 males. Chemistry achievement test (Cat) was used to collect data for the research. Richardson formula 21 was used to establish reliability for Cat, it was 0.79. The research used quasi experimental design. Analysis of covariance (ANCOVA) and descriptive statistics were used in the analysis of data. It was observed that teaching electronic configuration using kitchen resources to play games enhanced the academic performance of Chemistry students. The null hypothesis which stated that there is no significant relationship between students' academic achievement when taught electronic configuration with kitchen games and without was rejected. The second hypothesis with respect to gender was retained as the result was not significant. Teachers are encouraged to play games using kitchen resources in the teaching of electronic configuration to make the learning environment relax which will make learning effective.
\end{abstract}

Keywords: Beans, games, kitchen resources, teachers, and students.

\section{Introduction}

Education, particularly Science and Technical education, is the 'factory' for the production of the needed technologists, technicians and craftsmen as well as skilled artisans who are required to turn the nation's economy around and usher in the desired technological advancement which is very much required for the elevation of Nigeria from a 'consumer nation' to a 'producer nation'; from a 'developing nation' to a 'developed nation'.Science subjects taught in secondary school consist of Chemistry, Physics, Biology, Mathematics, Agriculture, Home Economics, Physical and Health Education. Chemistry is vigorously described as the queen of science. Chemistry occupies an enviable position in the senior Science national curriculum. Chemistry education is a veritable tool for national development. Realizing the role science plays in achieving self-reliance and intellectual development, one tries to find the place of Chemistry in Science (Emendu, 2014).

Chemistry is the study of matter and energy and the interaction between them. Chemistry is everywhere in the world around you! It is in the food you eat, clothes you wear, water you drink medicines, air cleaners, you name it (Helmenstine,2016). Chemistry sometimes is called the "central science" because it connects other sciences to each other such as Biology, Physics, Geology and Environmental Science.

Emendu's (2014) study on 'The Role of Chemistry Education in National Development' observed that the means scores of ; Chemistry education plays a major role in technological product of chemical industries, all manufacturing industries made use of chemical in their production, knowledge of Chemistry education fasten technology productivity of an indusrtry, Chemistry education helps in the invention of many products in the industries, raw materials used in chemical industries are Chemically based, improvement in chemical education enhances improvement in technology, skills learnt in Chemistry education are needed in chemical industry were 
statistically significant. It is obvious that Chemistry education plays a vital role in all aspects of technological practices with particular reference to chemical industries. This study shows that the teaching and learning of chemistry is basic for the development of chemical industries. With sound industries in the country the economy will boost, business will increase, and the environment in which they are processed will employ people in production. Teaching and learning is enormous in the development of chemical industries, that is, chemical industries employ the knowledge of chemistry in their work for their development. Chemistry education not withstanding helps in national development because chemistry helps in our daily lives. Without chemistry there is no chemical industry. Without chemical industry there is no productivity and without productivity there is no development. Hence, any government conscious of its responsibility should keep teachers and students at a reasonable motivational level towards learning of chemistry as this will encourage chemistry education which its role in chemical industries cannot be overestimated.

In as much as chemistry education and Chemistry is important, Nigerian students have had a persistence low performance in Chemistry examination both in internal and external examinations. Sakiyo \& Badau (2015) conducted a research on chemistry performance of students in WASSCE who had credit pass and obtained the following results: 44.44\%, 43.69\%, 50.70\%, 49.54\%, and 43.13\% for 2008, 2009, 2010, 2011 and 2012 respectively. From the above result, it is clear that there is a marginal decline in students' academic performance in Chemistry.

Researchers have discovered that there exist a relationship between students' attitude/interest, previous preparation, study style, parental involvement, teacher's expectancy and students' academic achievements (Edeh \& Vikoo, 2013). Others include teachers methodology, lack of practical's, books written by foreign authors, insufficient qualified teachers (Ojo, 2001 and Akinola 2006). Most students taking chemistry do not plan to pursue a career in chemistry. They take chemistry simply because those courses are prerequisites for degrees in fields of their interests, medical science or pharmacy or nursing for instance. Hence, lack of incentives is a profound obstacle to learning. On the other hand, chemistry contains an abundant amount of abstract concepts, which necessitates significant time and effort commitments from the students. The contrast between the low inputs and high demands results in unsatisfactory performance on the students' side and frustration on the instructor's side( Wu and Foos 2010).

Although the motivation enhancement in chemistry career demands national efforts in terms of promoting science and technology, increasing job opportunities, improving salary dynamics etc., a student's interest is another motive that is not justifiable from an economic perspective. For instance, some kids practice for hours in their spare time creating arts, playing instruments, perfecting their skills in sports or playing games simply because they are interested in those practices (McGonigalin Coveyou 2017).

Thus, chemistry instructors may also improve students' learning by inspiring students' interest. The question is "is chemistry really interesting?" Ironically, the answer is only "yes" to a limited number of chemists but not to the general public due to the adoption of tedious teaching methods in chemistry teaching. The purpose of this article is to find out the effect of teaching electronic configuration using kitchen resources (beans). My science box 2017, has suggested that beans can be used to teach electronic con figuration but there was no empirical finding as to the effectiveness in enhancing academic performance of students. This paper investigated the impact of teaching electronic configuration using kitchen resources (beans) on academic performance of students.

\section{Literature Review / Theoretical Underpinning}

Constructivist and conceptual change theory was pioneered by Jean Piaget. Constructivism is a learning theory and epistemology that has influenced much of science education lately. It states that learner constructs their own knowledge of the world through their past experiences. Students therefore do not learn by sitting in the classroom listening to the teacher, memorizing repackaged assignments and spitting out answers. 
They must talk what they learn, write about it, relate it to past experiences and apply it to their daily lives. They must make what they learn part of them. Teaching is the act of impacting knowledge and in doing so, teachers are minded that learning will only take place when the learner is engaged with the subject matters that the instructor intends. Three important factors that are very crucial in teaching and learning are; what the learner already know, the abilities of the learner and motivation. Teachers are to be reminded that the old Chinese Proverb (Chinese Confucian Philosopher Vunzi, 312-230BC) which states:

\author{
"Tell me, I will forget \\ Show me, I will remember \\ Involve me, I will understand"
}

is still applicable in our $21^{\text {st }}$ Century.

Looking at Rye (2005)'s principles for interaction in classroom pedagogical processes can then be codified into three types of teaching and learning processes, particular in adult(teacher) and child (learner) situation as:(a) teaching model where teacher initiates games, models and mediate tools, facilitate and promotes reflection (b) cooperation models where teacher and pupils are seen as collaborators and create joint activities and (c) autonomous models when teacher organizes the environment, observes self-initiated play and supports if necessary.. Mercer (2002) says that the quality of children's educational experiences is significantly affected by the extent to which their dialogue with the teacher gives what they are doing in class the continuity of meaning and a comprehensible and worthwhile purpose. Albert Einstein, Robert Burnswood and Charles Darwin suggested that rich and playful early childhood experiences with science had an impact of their learning and interest in science. Their interest were playing with physical gadgets, playing with mechanical construction sets, working with electricity and enjoying experiment that included "messing around". One remarkable thing about games is that they remove much of the intimidation inherent in the learning process (e.g. the feeling of dread that surfaces whenever students are faced with new vocabulary, multi-step processes and/or complex concepts). Watch a group of students play a game they are familiar with, and this becomes so obvious.

Games also transform the discomfort and psychological obstacle of 'failure' into an opportunity to iterate toward success. Students study what they need to learn in order to excel at a game, even when they make major mistakes. Games stimulate a deeper level of engagement around an idea and therefore a deeper level of understanding of that idea. Games also speed up the 'fail, learn, grow' iterative loop, and - most importantly without the emotional weight of grades and tests. Those can come later.

And for those students who may be a bit worried about working in groups ... have you seen how they act with their friends on the playground? Or around a board game or foots ball table? Even inside of the class, games can promote that same spirit of camaraderie and comfort ability, hopefully promoting group interaction over a multitude of complex topics A good game provides an opportunity to participate not only verbally and visually, but also in a tactile way as well. This is a breakthrough for more kinetic learner types ( Coveyou 2017).

\title{
3. Research Methodology
}

The research design used for this paper was a pretest-posttest control group quasi-experimental design. The sample consisted of 100 Senior Secondary School II Chemistry students from two schools in one Local Government Area in Ikom Education Zone. These schools were selected using the random and purposive sampling methods. There were 50 students each in the experimental and control groups. The experimental groups were taught electronic configuration using beans to play game. The control group was taught using conventional teaching method without game. A 50-item five-response option objective test (Chemistry achievement test, CAT) developed by the researchers was used as the pretest and posttest. The CAT items which were drawn to cover all the sub-topics of electronic configuration on a well-planned test blue-print were rearranged with its options in pretest and posttest to have different numbering so as to give a vague impression that the tests were different. The reliability of CAT was estimated to be 0.79 . Treatment lasted for a period of 
four weeks. The first author taught the experimental groups while the normal class teachers taught the control groups. The data collected with CAT were analyzed using a $2 * 2$ analysis of covariance (ANCOVA).

\section{Findings}

TABLE 1: Mean, Standard Deviation and Summary Of 2x2 Analysis of Covariance of Effect of Treatment and Gender on Ss2 Chemistry Students' Academic Performance in Electrochemistry.

\begin{tabular}{|c|c|c|c|c|c|c|}
\hline Treatment & \multicolumn{2}{|l|}{ Gender } & Mean & \multicolumn{2}{|c|}{ Std. deviation } & $\mathrm{N}$ \\
\hline \multirow[t]{3}{*}{ Experimental } & \multicolumn{2}{|l|}{ Male } & 38.12 & \multicolumn{2}{|c|}{7.88} & 22 \\
\hline & \multicolumn{2}{|l|}{ Female } & 37.06 & \multicolumn{2}{|l|}{8.64} & 28 \\
\hline & \multicolumn{2}{|l|}{ Total } & 37.67 & \multicolumn{2}{|l|}{8.19} & 50 \\
\hline \multirow[t]{3}{*}{ Control } & \multicolumn{2}{|l|}{ Male } & 17.13 & \multicolumn{2}{|l|}{4.26} & 18 \\
\hline & \multicolumn{2}{|l|}{ Female } & 14.74 & \multicolumn{2}{|l|}{6.07} & 32 \\
\hline & \multicolumn{2}{|l|}{ Total } & 15.83 & \multicolumn{2}{|l|}{5.40} & 50 \\
\hline \multirow[t]{3}{*}{ Total } & \multicolumn{2}{|l|}{ Male } & 31.62 & \multicolumn{2}{|l|}{15.72} & 40 \\
\hline & \multicolumn{2}{|l|}{ Female } & 28.51 & \multicolumn{2}{|l|}{16.66} & 60 \\
\hline & \multicolumn{2}{|l|}{ Total } & 31.25 & \multicolumn{2}{|l|}{16.35} & 100 \\
\hline $\begin{array}{l}\text { Sources of } \\
\text { variation }\end{array}$ & Sum of squares & df & Mean squares & $\mathrm{F}$ & Sig level & Partial Eta square \\
\hline Corrected Model & 56455.98 & 4 & 13854.995 & 249.663 & $.000 *$ & .723 \\
\hline Intercept & 23242.512 & 1 & 23242.512 & 330.237 & $.000 *$ & .501 \\
\hline Pretest & 2014.541 & 1 & 2014.541 & 31.682 & $.000 *$ & .151 \\
\hline Treatment & 50072.013 & 1 & 50072.013 & 1014.110 & $.000 *$ & .713 \\
\hline Gender & 102.987 & 1 & 102.987 & 2.117 & .112 & .009 \\
\hline $\begin{array}{l}\text { Treatment X } \\
\text { Gender }\end{array}$ & 11.043 & 1 & 11.043 & .164 & .408 & .001 \\
\hline Error & 11091.018 & 195 & 430.133 & & & \\
\hline Total & 311463.000 & 100 & & & & \\
\hline Corrected total & 71951.000 & 223 & & & & \\
\hline
\end{tabular}

R. squared $=723($ adjusted R squared $=.715)$ F-critical $=3.94 * \mathrm{P}>.05$

Hypothesis 1: There is no significant difference between the academic performance of SS2 chemistry students taught electronic configuration using kitchen games and those taught without kitchen resources.

Hypothesis 2: There is no significant difference between the academic performance of SS2male and female chemistry students taught electronic configuration using kitchen games.

Examination of Table 1 showed that in the experimental group, the male students had a higher mean score $(\mathrm{x}=38.12)$ than their female counterparts $(\bar{x}=37.06)$ in the same vein; the males taught electronic configuration without kitchen games had a higher mean $(\bar{x}=17.13)$ than female students $(\bar{x}=14.74)$. Male students taught with kitchen games had a higher mean score $(x=38.12)$ than males in the control group $(x=17.13)$. Females in the experimental group also had higher mean $(x=37.06)$ than female in the control group $(x=14.74)$. Students taught electronic configuration with kitchen games had higher mean score $(x=37.67)$ than students taught Thermochemistry without kitchen resources $(\mathrm{x}=15.83)$. That same Table 1 indicated that treatment was significant $(\mathrm{F}=1014.110, \mathrm{P}<.05)$; gender was not significant $(\mathrm{F}=2.117 ; \mathrm{P}>.05)$; interaction of treatment and gender was not significant $(\mathrm{F}=0.164 . \mathrm{P}>.05)$. The first null hypothesis was rejected and the second null hypothesis was retained.

\section{Discussion}

The first Hypothesis sought to find out if there was a significant difference between the academic performance of SS2 chemistry students taught electronic configuration using kitchen games and those taught without kitchen games. This study showed that treatment was significant $(\mathrm{F}=1014.110, \mathrm{P}<.05)$; the importance and significant role played by Kitchen games on students' academic performance, especially in Chemistry. It had a positive influence in performance Chemistry. It made learning fun and exciting there by leading to improved students' performance. 
The second hypothesis sought to find out if there was significant influence of gender on SS2 Chemistry student's performance when taught electronic configuration using kitchen games. The result of the $2 \times 2$ Analysis of Covariance in gender and treatment as shown in Table 1 earlier revealed that, there was a non-significant interaction effect of gender and treatment on academic performance of SS2 Chemistry students. The critical Fvalue of 3.94 was higher than the calculated F-value of 0.164. This implies therefore that gender do not interact with treatment to affect SS2 Chemistry students when taught electronic configuration using kitchen games. The implication of this study is that, irrespective of gender student's academic performance taught electronic configuration using kitchen games was profitable.

\section{Conclusion and Recommendations}

The study showed the importance and significant role played by method of presenting lesson on students' performance, especially in Chemistry. Games have positive influence in students' performance in Chemistry. It was therefore observed that using beans to play game assisted teachers in making lesson delivering easier. It allowed students to interact better in their lesson. It made learning exciting and fun. It encouraged active participation, bringing learning homewards and often improved and enhanced students' performance. It would also be important to include the use of games as parts of the contents of chemistry teacher retraining programs. Students should be taught on how to produce their own games.

\section{References}

[1] Akinola, B. M. A. "Reasons for mass failure in senior secondary chemistry in Ijebu east municipality section of again condition". Oro science education Journal, 4(5\&6), pp 8-19. 2006

[2] Chun Wu and Jordan Foos. Making Chemistry Fun to Learn Lit InfComputEduc J. Mar 2010; 1(1): pp 3-7.

[3] Coveyou. J. Game on! Teaching science with games, 2017

[4] Edeh, I. E. and Vikoo, B. Some factors affecting the performance of secondary school students in chemistry, Journal of Education and practice, 4(7), pp 222-1735, 2013.

[5] Emendu, N. B. The role of chemistry education in national development.International Journal of Engineering and Sciences (IJES), 3(3), pp 12-17, 2014.

[6] Helmenstine A. M. Science experiments from the kitchen. 2011. Retrieved from http://www.about.comguide,.

[7] Herron JD. The Chemistry Classroom: Formulas for Successful Teaching. American Chemical Society; Washington, DC, USA: 1996.

[8] Idemokon, B. U. Constraining factors to effective integrated science curriculum implementation in Nigeria secondary school, 1997. (Post-graduate seminar paper).

[9] Mercer, N. Developing Dialogues. In G. Wells \& G. Claxton (Eds.), Learning for Life in the 21st Century: Sociocultural Perspectives on the Future of Education (pp. 141-153). GB: Blackwell Publishing, 2002.

[10] Ogwu, O. "Improvisation of instructional materials for the teaching of agricultural science in secondary school's Journal of CUDIMAC, 1(1), pp.1-2, 2005.

[11] Ojo, M. O. Problems training science and mathematics.Being paper presented at train the trainer workshop for science and mathematics instructors in schools of education in six Geo-political zone of Nigeria in Nigeria, 2001.

[12] Rye, H.. The foundation of an Optimal Psychosocial Development.In Johnsen, Berit H. (ed.), Socio-Emotional Growth and Development of Learning Strategies, 2005. Oslo: Oslo Academic Press.

[13] Sakiyo, J and Badau, K. M. Assessment of the trend of secondary school students' academic performance in the sciences, mathematics and English: Implication for the attainment of the millennium development goals in Nigeria. Advances in social science research 2 (2) pp 31-38, 2015. 
[14] Science Box: Hands-on science curriculum for the adventurous teacher. Teaching electron configuration

[15] Vunzi 312-230BC in G. R. Shelton and D. Mason," ICT in teaching and learning chemistry activities on the IPAD”. AJE.4 ed., Vol.40,2014, pp 183-188.

\section{Appendix}



(Adapted from My Science Box) Bohr Model tells students to envision a football stadium where different people are assigned different seats. Generally, people want to sit closest to the field (the nucleus) so they can be nearest the action. Also, different sections of this stadium have more cushy seats than others - first come, first served. Thus, certain subshells fill before others in a given orbital. Beans from the kitchen were used to represent and build 2D models of atoms. The diagram represents an electron seating chart view of the atom. Students can build larger and larger atoms using the diagram as a "placemat" to place each electron. 